\title{
eCOti
DiAno
}

Revista Mídia e Cotidiano

ISSN: 2178-602X

Artigo Seção Livre

Volume 15, Número 1, jan./abr. de 2021

Submetido em: 25/09/2020

Aprovado em: 25/11/2020

\section{Microempreendedor individual e a noção de cidadania empresarial}

\section{Individual microentrepreneur and the concept of corporate citizenship}

\section{Microemprendedor individual y el concepto de ciudadanía empresarial}

\author{
Julia SALGADO ${ }^{1}$
}

\section{Resumo}

Neste artigo, realizo uma análise de discursos midiáticos e institucionais sobre o microempreendedor individual (MEI) com o objetivo de pensar no conceito de cidadania empresarial, constantemente usado na promoção desta figura. Recorrendo a um referencial teórico proveniente sobretudo das ciências sociais e dos estudos culturais, reflito sobre as transformações do conceito de cidadania em um cenário neoliberal. Distanciando-se de uma concepção tradicional, segundo a qual a cidadania é pensada em termos coletivos e inclusivos, sugiro que a noção de cidadania empresarial se fundamenta sobre valores individualistas, recorrendo à noção de mérito para justificar seu restrito acesso.

Palavras-chave: MEI. Cidadania empresarial. Discursos midiáticos. Subjetividade. Mérito.

\begin{abstract}
In this article, I carry out an analysis of media and institutional discourses about the individual microentrepreneur (MEI) with the objective of thinking about the concept of corporate citizenship, constantly used in the promotion of this figure. Using a theoretical framework derived mainly from sociology and cultural studies, I reflect on the transformations of the concept of citizenship in a neoliberal scenario. Moving away from a traditional conception, according to which citizenship is thought in collective and inclusive terms, I suggest that the notion of corporate citizenship is based on individualistic values, using the notion of merit to justify its restricted access.
\end{abstract}

Keywords: MEI. Corporate citizenship. Media discourse. Subjectivity. Merit.

\section{Resumen}

En este artículo realizo un análisis de los discursos mediáticos e institucionales sobre el microempresario individual (MEI) con el objetivo de reflexionar sobre el concepto de

1 Pós-doutoranda no PPGCOM-UFRJ, com auxílio FAPERJ. E-mail: prof.juliasalgado@gmail.com. ORCID: 0000-0001-8852-1289. 
ciudadanía corporativa, utilizado constantemente en la promoción de esta figura. Utilizando un marco teórico derivado principalmente de la sociología y los estudios culturales, reflexiono sobre las transformaciones del concepto de ciudadanía en un escenario neoliberal. Alejándonos de una concepción tradicional, según la cual la ciudadanía se piensa en términos colectivos e inclusivos, sugiero que la noción de ciudadanía corporativa se basa en valores individualistas, utilizando la noción de mérito para justificar su acceso restringido.

Palabras clave: MEI. Ciudadanía corporativa. Discurso de los medios. Subjetividad. Mérito.

\section{Introdução}

Em meados de setembro de 2020, matéria da seção Economia do Portal G1 atesta: "País ganhou quase 1 milhão de MEIs desde o início da pandemia"2. Na reportagem, testemunhos de novos microempreendedores individuais embasam o argumento central do texto: com "o aumento do desemprego e maior flexibilização das relações de trabalho, muitos brasileiros têm sido empurrados para o chamado 'empreendedorismo por necessidade' como uma forma de sobrevivência". De acordo com dados do IBGE, trazidos pela própria matéria, 1,092 milhão de empregos formais foram perdidos desde o início da pandemia, o que, de certa maneira, explicaria tamanha procura pelo MEI no país.

Uma análise mais detalhada nos dados de adesão ao MEI, no entanto, nos mostra que, embora o alto desemprego gerado pela pandemia tenha intensificado a formalização de microempreendedores ao longo de 2020, a grande procura pela categoria segue uma tendência crescente desde sua criação, em 2009 (ver Gráfico 1) ${ }^{3}$. Portanto, o que assistimos hoje pode ser visto como uma intensificação, no contexto da pandemia, de uma tendência já estabelecida na sociedade brasileira de valorização e engajamento à cultura do empreendedorismo.

\footnotetext{
${ }^{2}$ Disponível em: https://g1.globo.com/economia/noticia/2020/09/19/pais-ganhou-quase-1-milhao-de-meis - desde-o-inicio-da-pandemia-veja-relatos.ghtml. Acesso em: 30 out.2020.

${ }^{3}$ Com a exceção do ano de 2008 , em que a taxa de adesão sofreu uma retração de $2 \%$, as adesões ao MEI seguem uma tendência de constante crescimento, com taxa média de $20 \%$ ao ano nos últimos 12 anos.
} 


\section{Gráfico 1 - Crescimento MEI entre 2009 e 2020}

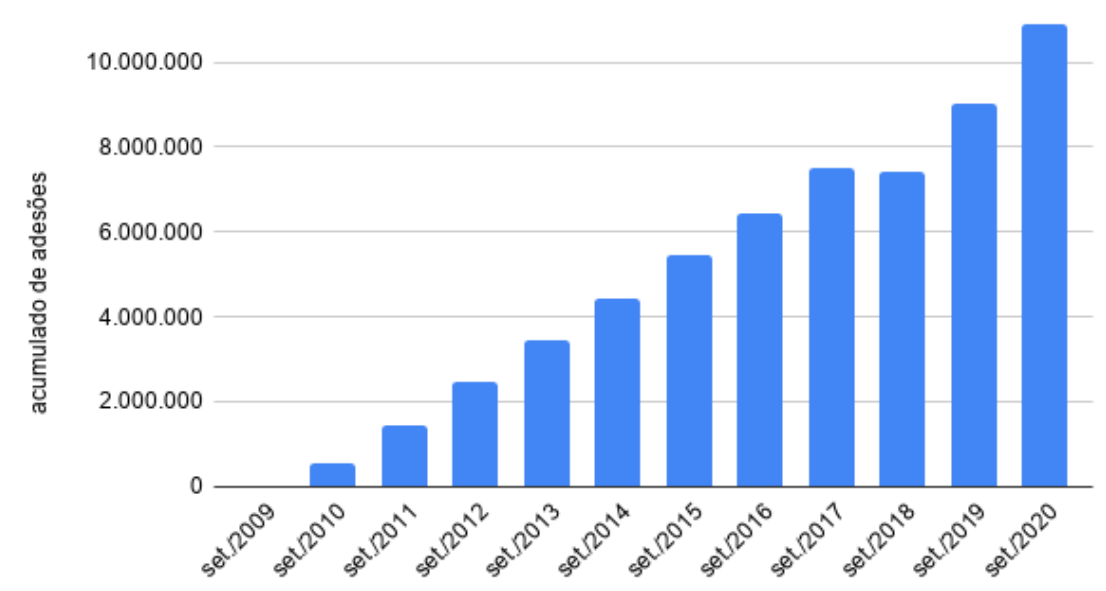

Fonte: Elaborado pela autora a partir de dados do Portal do Empreendedor.

Mas como, e sob quais condições, foi possível que o empreendedor, figura fortemente relacionada à cultura e à mentalidade anglo saxônica e protestante, se tornasse tão popular em um país como o Brasil? Este questionamento norteou algumas de minhas pesquisas mais recentes, dando, entre outros, origem a este artigo. Através da análise de discursos midiáticos e institucionais, busquei compreender os sentidos e significados atribuídos, ao longo desse período, a esta figura e percebi que a figura do empreendedor vai progressivamente se diversificando.

Se, até a virada do século XXI, os modos de ser empreendedor estavam fortemente associados à figura masculina, de meia idade, que desenvolve uma atividade empresarial e pertence majoritariamente a uma classe média-alta; com o passar dos anos tais formas vão se multiplicando, passando a incluir também figuras femininas, jovens (e mesmo crianças), que pertencem a diversas classes sociais e desenvolvem variadas atividades econômicas, não necessariamente ligadas a uma atividade empresarial. Como profetizara Michel Foucault no final da década de 1970, "ser empreendedor" se torna mais do que uma atividade econômica: é um modo de ser e estar no mundo, uma característica subjetiva cada vez mais positivada e requerida. E isto também seria (cada vez mais) válido para o cenário brasileiro.

Sintoma dos tempos, a disseminação de múltiplos modos de ser empreendedor hoje reflete uma mudança mais ampla e estrutural no mercado laboral, que não se baseia 
mais essencialmente no trabalho estável e assalariado, mas confere cada vez mais importância e espaço ao trabalho autônomo e sem vínculo empregatício. Numa autotransformação necessária à sua perpetuação e disseminação, o empreendedorismo, enquanto modelo de atuação econômica, diversifica-se para conseguir dar conta de todo contingente de trabalhadores que passaria a englobar.

Aqui, trago reflexões sobre um dos modos atuais de ser empreendedor: o microempreendedor individual, ou o MEI, como é mais conhecido hoje no país. A figura jurídica foi criada pelo governo brasileiro em 2009, com o objetivo de formalizar cerca de 10 milhões de trabalhadores informais. A meta foi alcançada em pouco mais de dez anos, em Abril de 2020. No Portal do Empreendedor, plataforma de informação sobre a categoria e de onde o processo de formalização é realizado, chama a atenção a frase ao lado do link que imperativamente conclama: "Formalize-se". Ali, lê-se: "Ao abrir sua empresa, você MEI terá cidadania empresarial [grifos meus]: CNPJ, direitos e benefícios"4.

Sendo a figura jurídica de uma nova - e mais baixa - faixa de tributação do país, os trabalhadores autônomos que atuam em quase quinhentas atividades podem formalizar seu negócio e, pagando atualmente (2020) cerca de 58 reais ao mês, obter benefícios previdenciários e mercadológicos. Com a nítida finalidade de trazer à legalidade (e, consequentemente, à tributação) milhões de pessoas que estão no mercado submerso, o MEI vem sendo descrito não apenas como uma inovação jurídico-tributária, mas também como um passaporte de acesso a produtos e serviços intangíveis a esse público, como concessões de crédito, cobertura previdenciária, apoio técnico e mesmo cidadania.

O processo de formalização é apresentado em termos de facilidade: todo feito online através do Portal do Empreendedor, é possível se tornar um MEI em alguns instantes, após o preenchimento das informações solicitadas. As condições de tal legalização são que o novo empresário tenha um faturamento anual de no máximo 81 mil reais; não tenha participação em nenhum outro empreendimento como sócio e tenha no máximo um empregado contratado com o salário mínimo. Os benefícios são: possuir um CNPJ, o que facilitaria a abertura de contas bancárias, pedidos de empréstimos e a

\footnotetext{
${ }^{4}$ Disponível em: http://www.portaldoempreendedor.gov.br/. Acesso em: 26 dez. 2019.
} 
emissão de notas fiscais; isenção de tributos federais e contribuição reduzida ao INSS, o que garante ao MEI acesso a benefícios como auxílio maternidade, auxílio doença e aposentadoria, entre outros.

No livro "5 anos: Microempreendedor Individual - MEI: um fenômeno de inclusão produtiva" (SEBRAE, 2015), que trata o MEI como um "fenômeno de inclusão produtiva", somos informados de que $27 \%$ do PIB brasileiro é gerado por pequenos negócios, o que faz com que o estímulo a programas como o MEI seja essencial por contribuir para a economia nacional. Ao contrário da progressiva diminuição de postos de trabalhos nas médias e grandes empresas, especialmente no setor industrial, o texto alerta que os pequenos negócios do país respondem "pela maioria dos empregos com carteira assinada abertos nos 10 anos mais recentes. Em 2014, foram registradas 717 mil vagas nos pequenos negócios frente a um saldo negativo de aproximadamente 45 mil nas empresas maiores" (SEBRAE, 2015, p. 7). Nesse contexto, a participação do novato MEI não seria nada desprezível na visão dos autores do livro:

O Brasil levou praticamente 514 anos para ter hoje 9,5 milhões de empresas de todos os portes. Em apenas cinco anos, os microempreendedores individuais, os chamados MEIs, já atingiram 4,7 milhões. Um fenômeno de inclusão produtiva jamais registrado no País, e provavelmente no mundo (Ibid., p. 11).

Representando, então, praticamente metade das empresas registradas no país, o MEI pode ser pensado como a materialização mais elementar do homo oeconomicus neoliberal estudado por Foucault (2008a): sob a égide do capitalismo pós-industrial, o trabalhador se transformaria necessariamente em uma empresa. Possivelmente, ao propor suas ideias no final da década de 1970, o filósofo francês não imaginava que a capilarização da empresa até o nível mais unitário da sociedade - o indivíduo - se daria do modo formal como acontece com o MEI, ou seja, pela transformação legal da pessoa física em pessoa jurídica. Foucault pensava na empresarização dos indivíduos em termos de lógica norteadora: se, com a proeminência da Teoria do Capital Humano, o indivíduo passa a ser entendido como seu próprio produtor, seu próprio investidor, sua própria fonte de renda; então nada mais razoável do que pensar nesse sujeito como sendo ele mesmo uma empresa. Tal visão abrangente nos modos a partir dos quais o homem ocidental é 


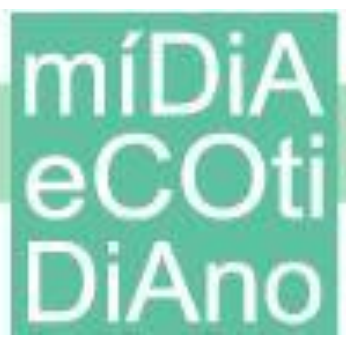

instado a encarar seu comportamento e seu modo de ser e estar no mundo a partir da segunda metade do século XX - como o solitário investidor dele mesmo, sua empresa individual - ganha, com o MEI, sua mais objetiva materialização.

Se, como objeto de estudo, o empreendedor é mais comumente encontrado em áreas como a Administração e a Economia, não deveria causar espanto que tal objeto se torne privilegiado também na Comunicação. Isso porque, enquanto campo de estudo, nos cabe atentar para as transformações nos modos através dos quais os sujeitos são instados a se subjetivar, se socializar e a produzir e consumir novas estéticas e retóricas. Com a crescente preponderância da mentalidade neoliberal em nossa sociedade, especialmente nas duas últimas décadas, assistimos ao proliferar do empreendedor como subjetividade privilegiada, ou "o homem ideal" como afirmou Sennett (2010) no fim do milênio passado. Neste milênio, não apenas ideal, o empreendedor se torna subjetividade normativa, que se diversifica em seus formatos e ganha crescente destaque na mídia (SALGADO, 2020).

Atentos a este crescente destaque midiático conferido à figura do empreendedor, diversos pesquisadores do campo da Comunicação se debruçaram sobre o tema. Vander Casaqui problematiza o ainda turvo conceito de empreendedor social, "um ator relativamente recente, que representa a lógica cultural do capitalismo contemporâneo" (CASAQUI, 2013a, p. 868) e que promoveria uma prática paradoxal à medida que concilia a busca pelo bem comum e, ao mesmo tempo, o culto por uma performance lastreada no individualismo, na eficácia e na concorrência (CASAQUI, 2013b). O autor, inclusive, coordenou por vários anos o GT "Cultura Empreendedora e Trabalho", no Congresso Internacional Comunicação e Consumo, da ESPM, que se tornou um espaço fecundo para pesquisadores interessados no tema. Dentre eles destaco, somente a título de menção, os trabalhos de Rafael Grohmann (entre outros, ver ROXO \& GROHMANN, 2015) sobre a influência do empreendedorismo no âmbito da atuação profissional jornalística, marcada pela flexibilização e precarização; de Marianna Ferreira Jorge (entre outros, ver SALGADO \& JORGE, 2019) sobre os desdobramentos do espírito empresarial na sociedade contemporânea; e Patrícia Matos (entre outros, ver MATOS, 2016), sobre trabalho móvel, juventude e o ethos empreendedor. 
A partir de um olhar atento a este objeto, intenciono discutir algumas transformações contemporâneas no conceito de cidadania, realçando as conexões entre a emergência de uma figura como a do MEI (e seu correlato conceito de "cidadania empresarial") e a crescente preponderância de uma racionalidade neoliberal e individualista. Em outras palavras, este trabalho tem como objetivo pensar de que maneira a criação de um novo "tipo de pessoa" (HACKING, 1985), afinado à mentalidade capitalista contemporânea, pode contribuir para a transformação do senso comum sobre os significados de um conceito tão caro à democracia, como o de cidadania. E como essa transformação pode representar novas formas de desigualdade que atualmente se revestem sob o discurso da "meritocracia".

Para buscar responder essa questão, examino aqui discursos sobre o MEI encontrados na Folha de S. Paulo entre 2009 e 2015, além de discursos institucionais retirados de materiais do Sebrae, principal entidade de promoção da categoria. Sugiro ser possível, através da análise de discurso, depreender alguns dos sentidos e significados que lhe são associados, assim como também as resistências a esses processos de significação. É estruturante para este trabalho o arcabouço teórico e conceitual proveniente do trabalho de Michel Foucault, seja em termos metodológicos - a partir da perspectiva da análise de discurso (2019) -, seja nas suas contribuições conceituais sobre o neoliberalismo e o homo oeconomicus contemporâneo como o "empreendedor de si mesmo" (2008a).

\section{Os discursos sobre o microempreendedor individual}

A primeira percepção ao analisar as diversas matérias e colunas opinativas sobre o MEI na Folha de S. Paulo é a racionalidade instrumental presente nos discursos, traduzida em dados numéricos e estatísticos. Em praticamente todas aparições do termo faz-se recurso aos números para justificar a importância do MEI na atualidade e para demonstrar seu crescimento e seu sucesso. Em coluna opinativa assinada em setembro de 2009 pelo então ministro da Previdência Social, José Pimentel, a nova figura é apresentada em termos quantitativos: "Onze milhões de homens e mulheres que trabalham por conta própria no comércio, na indústria e na prestação de serviços começam a ter as suas atividades formalizadas em todo o país graças ao Programa do 


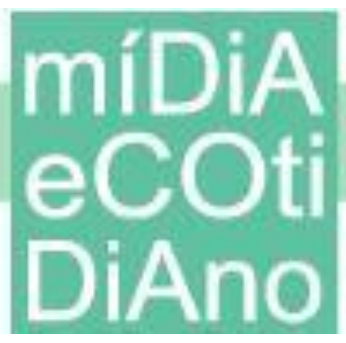

Empreendedor Individual” (PIMENTEL, 2009, p. A3). Após expor as características da modalidade e as vantagens de adesão, o político recorre novamente à precisão dos dados numéricos para atestar a importância do programa: "Para ter uma ideia da importância dos empreendedores individuais, as micro e pequenas empresas geraram mais de 450 mil empregos em todo o Brasil somente no primeiro semestre de 2009. Os dados são do Ministério do Trabalho e Emprego." (Ibid.)

Alguns anos depois, os números são novamente acionados, agora para comprovar o sucesso do programa, que partiu de 49 mil inscrições em 2009 e chegou a 2,1 milhões em 2012. O crescimento exponencial continuaria, segundo estudo do Sebrae: "Hoje, o Brasil tem 2,1 milhões de MEI, mas deve chegar a 4,3 milhões em 2014, quando as MPE serão 4,2 milhões" (GOMES, 2012, p. B6). O "fetiche dos números", que revela o "espírito (quantitativo) da [nossa] época" (SOUZA, 2009, p. 16), reaparece em praticamente todas as menções ao MEI na Folha. Para Jessé Souza (2009), a valorização de dados numéricos e de estatísticas reflete uma visão de mundo economicista e redutora, segundo a qual se crê que cifras seriam capazes de traduzir a realidade social. Jerôme Gautié, cientista social e economista, compartilha da mesma opinião - ainda que através de argumentos mais pragmáticos. Segundo ele, embora as abordagens que privilegiam as estatísticas macrossociais tenham sido importantes no passado, por permitirem ao Estado formar "os instrumentos de uma boa intervenção pública” (GAUTIÉ, 1998, p. 67), atualmente tais enfoques seriam inadequados ao entendimento de uma realidade social cada vez mais complexa e impregnada de múltiplas individualidades - o que faz com que as estatísticas sejam abstrações totalizadoras e distantes do indivíduo.

Nas poucas vezes em que o "economicismo" compartilha espaço com um tratamento mais "humanizado" do tema, trazendo, para além dos números, o testemunho de indivíduos que se tornaram MEIs, percebe-se o privilégio em relatar casos de sucesso, geralmente de indivíduos de classe média (ainda que média-baixa). Assim, os exemplos de insucesso do MEI são silenciados ou minimizados, como no Caderno Negócios de 19/08/2012, que promete contar as receitas de MEIs que elevaram seu faturamento após registro formal. A reportagem especial traz os relatos dos dez primeiros cadastrados no MEI, que "revelam os desafios e benefícios da categoria" (GUTIERREZ, 2012). Três deles teriam prosperado tanto que mudaram de faixa empresarial, deixando de ser MEIs 


\section{míDiA

e se tornando microempresas. Outros cinco falam de "benefícios" do programa, como o acesso ao crédito e a formas de pagamento como o cartão de crédito; a possibilidade de emitir notas fiscais e de conquistar novos mercados.

Os principais obstáculos do programa (apresentados não como "malefícios" em contraponto aos "benefícios", mas sim "desafios" a serem superados) seriam o baixo teto de faturamento e a impossibilidade de contratar mais de um funcionário, fatores que teriam, inclusive, levado três deles a virar microempresas. Dos dez exemplos, apenas dois não teriam prosperado: a cozinheira Elaine Souza, que ao final de um ano desistiu de ser MEI quando percebeu que as despesas eram maiores do que as receitas. E o cabeleireiro David Soares, que não conseguiu empréstimos em bancos e, com isso, não atingiu sua expectativa de crescimento. Ao contrário dos exemplos bem-sucedidos, destacados na matéria com fotos e posição no alto da página, Elaine e David ocuparam a parte de baixo da página, sem grandes destaques.

A valorização, pela Folha, dos casos de MEIs bem-sucedidos traz um outro dado importante: em geral os testemunhos são de indivíduos cuja opção pelo empreendedorismo não se dá tanto em termos de necessidade, mas sim de oportunidade. Em dezembro de 2015 o Caderno Negócios apresenta dicas para profissionais autônomos, modalidade que graças ao MEI prosperava no Brasil. Títulos como "Independente S.A." e "Carreira solo" sintomaticamente apresentam a guinada individualista do mercado de trabalho, no qual,

Seja por opção ou por necessidade, o trabalho autônomo vem crescendo no Brasil. Entre dezembro de 2014 e de 2015, o número de microempreendedores individuais (MEIs) aumentou 21,3\%. Independência profissional e flexibilidade de horários são as principais vantagens apontadas por quem trabalha nessa modalidade. A autonomia, porém, traz consigo alguns problemas. Definir o preço do serviço oferecido e fazer o controle financeiro são algumas das dificuldades que a modalidade impõe (PERRIN, 2015, p. F54).

Apesar de mencionar a necessidade como possível fator na decisão de ser autônomo, os exemplos dados na matéria são todos de pessoas que optaram, de forma voluntária, por sair de seus empregos - para ter mais tempo, mais flexibilidade, menos estresse: “"Eu estava estressado e descontente. Busquei qualidade de vida. Hoje tenho 


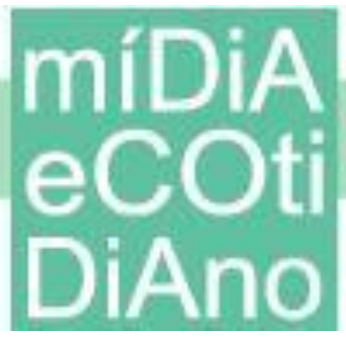

uma remuneração que entendo como ideal para mim trabalhando menos', afirma o engenheiro ambiental Raoni Santos”; “Nenhum benefício paga o fato de ter tempo', afirma a maquiadora Bárbara Zacarias" (Ibid.). Ou seja, o ponto de vista escolhido pelo jornal para abordar o crescimento do trabalho autônomo - sendo o MEI a sua grande exemplificação - privilegiou um perfil profissional com mais recursos e menos necessidade materiais, de onde decorre que os "problemas" enfrentados são de ordem operacional (precificação e controle financeiro, por exemplo), e não estrutural (como insegurança e precariedade econômicas ou falta de entrada no mercado).

Enquanto a Folha, em suas reportagens, prioriza uma representação do MEI através de personagens que decidiram livremente pelo empreendedorismo, sem grandes constrangimentos socioeconômicos, o discurso de autoridades no jornal (como ministros, deputados e gestores de autarquias e confederações) apresenta o MEI como sendo uma ferramenta de inclusão socioeconômica e, portanto, eminentemente destinada àqueles em estado de exclusão. É o caso de Guilherme Afif Domingos, que junho de 2015 assina coluna na seção Opinião intitulada "Batalhadores do Brasil”. Com clara referência ao livro organizado por Jessé Souza, Os batalhadores brasileiros (2012), Domingos anuncia, em tons comemorativos, a marca de "cinco milhões de brasileiros formalizados, que passaram a contar com a segurança do Estado e o acesso a direitos previdenciários", o que constituiria "uma vitória da classe batalhadora de nosso país" (DOMINGOS, 2015, p A3). O MEI é apresentado como política pública inovadora e grandiosa, capaz de tirar da marginalidade mais de 10 milhões de pessoas que, apesar de terem sempre procurado "garantir sua sobrevivência por meio de muito trabalho e de criatividade" (idem), ainda eram privadas do status de cidadania.

O MEI é hoje, no mundo, o maior programa de inclusão econômica e social. Quando levamos a ideia do projeto para o presidente Lula, em 2003, falávamos em dar cidadania a mais de dez milhões de trabalhadores informais. Em seis anos de trabalho (2009-2015), chegamos aos cinco milhões - e vamos formalizar o restante nos próximos cinco anos. Estamos falando de cidadania e formalização que tiraram cidadãos da marginalização, da informalidade, garantindo a eles o acesso a benefícios sociais que todo brasileiro deve ter. Acreditando na importância dessa inclusão, batizamos o carnê enviado ao MEI de Carnê da Cidadania (Ibid., grifos meus). 
Os benefícios aos quais o então ministro se refere são: o direito à Previdência Social; o registro formal do empreendimento, com a obtenção de CNPJ, o que possibilita emitir notas fiscais e ampliar o acesso a mercados (inclusive o mercado governamental) e a possibilidade de pleitear crédito subsidiado em instituições bancárias. $\mathrm{O}$ acesso a esses benefícios, que se dá por meio do registro (a "formalização"), chegaria mesmo àquela parcela da população mais carente, como os cadastrados no maior programa de redistribuição de renda do país, o Bolsa Família: "Um fato importante é que cerca de 500 mil pessoas cadastradas no Bolsa Família fizeram do MEI a alternativa para buscar o seu sustento" (Ibid.). Longe, portanto, de representar apenas aqueles com absoluto livrearbítrio na decisão pelo seu destino profissional, o MEI abarcaria também indivíduos situados na posição mais baixa da pirâmide social.

De acordo com Afif Domingos, o denominador comum a todos os cadastrados no MEI, independentemente de sua situação socioeconômica, seria o famoso sonho do negócio próprio: "O sonho do brasileiro de trabalhar por conta própria tem no MEI a sua maior expressão - e o seu ponto de partida para a autossustentação. Todos sonham em crescer" (Ibid.). Destacando a prática empreendedora como um desejo comum a todos os brasileiros, algo que agora estaria ao alcance de qualquer um através da figura do MEI, percebemos no discurso uma dupla naturalização: de um lado, a crença de que o empreendedorismo é a mais eficaz (ou mesmo a única) arma de combate à falta de renda e ao pauperismo; do outro, um senso comum, cada vez mais disseminado, de que todos os brasileiros têm um "espírito empreendedor" ou uma "vocação natural a empreender". O texto escrito por Domingos traz certo número de elementos sobre os quais podemos refletir e que aparecem na maioria dos textos sobre o MEI assinados por autoridades públicas e institucionais, como demonstro a seguir.

A primeira marca significativa é a implícita "redenção" do Estado. Na coluna de Domingos, mas também em muitos outros textos opinativos sobre o MEI, o Estado brasileiro, que sempre foi acusado pela sua ineficiência, burocracia e indevida apropriação da renda nacional (SALGADO, 2020), é exaltado pela capacidade de ter se modernizado e criado leis mais eficazes e que libertam os empreendedores de amarras burocráticas e tributárias. Enquanto em 2006 o próprio Afif Domingos acusava, na Folha, o Estado de distribuir "benesses à custa de enormes déficits públicos e da estagnação das 


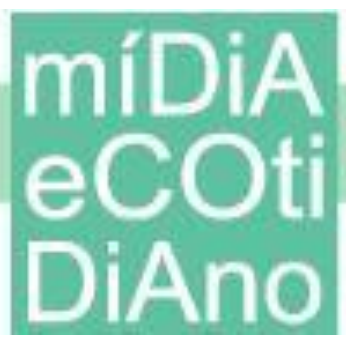

empresas e da iniciativa privada", e duvidava da sua aptidão em "assegurar o bem-estar de todos" (2006, p. A3 apud SALGADO, 2020, pg. 86), a partir de agora o Estado seria aquele que provê segurança e acesso a direitos aos "Batalhadores do Brasil".

Os avanços socioeconômicos promovidos por uma figura como a do MEI são algumas vezes equiparados àqueles conquistados com a legislação trabalhista instituída por Getúlio Vargas, o que não deixa de ser ao mesmo tempo um dado irônico e bastante sintomático de cada momento histórico: se, no início do século XX, a Consolidação das Leis do Trabalho (CLT) espelhava as demandas e a estrutura do mercado laboral daquele período; menos de cem anos depois tal modelo mostra seu declínio, sendo o trabalho autônomo e empreendedor seu mais cotado sucessor. A ambiguidade contida na figura do MEI - que podemos entender como transitória entre o "trabalhador CLT" e aquele totalmente autônomo - está numa certa tentativa de assegurar um mínimo de garantias conquistadas pelos trabalhadores (como aposentadoria, auxílios maternidade e doença, entre outros) em uma nova atuação mercadológica, não mais marcada pelo assalariamento. Tal busca pela conciliação de segurança e autonomia reflete, de certa maneira, a ambiguidade nos anseios individuais contemporâneos. Se, como afirmam diversos discursos da mídia, existe o difuso sonho do negócio próprio; não se pode ignorar a ânsia por segurança, refletida na busca pela carreira de serviço público. Dessa maneira, falas que atestam a ubiquidade do "sonho de ser o próprio chefe" operam uma naturalização seletiva e totalizante, que se presta a justificar o empreendedorismo como a única alternativa possível.

A inclusão econômica e social possibilitada pelo acesso a serviços e direitos que transformam o sujeito marginalizado em cidadão formalizado se faz através de um cadastramento, uma visibilidade formal do indivíduo perante o Estado. Ora, tal registro nada mais é do que uma tecnologia de poder governamental, capaz de gerar um saber (informações, dados, estatísticas) sobre uma população determinada (trabalhadores autônomos). Sabemos, com Foucault (2008a), que a racionalização de um saber ligado a uma população é justamente o que o autor chamou de biopolítica. O MEI, portanto, deve ser visto como uma biopolítica que visa organizar, cultivar, proteger e fazer multiplicar sujeitos empreendedores. 
O interessante, no entanto, é perceber que a racionalização sobre tal população empreendedora não é apenas desenvolvida pelo Estado, mas de forma crescente por outro importante agente social: as instituições financeiras. Através da ideia de "cidadania empresarial", algo que compreenderia o acesso a serviços financeiros como contas bancárias, máquinas de cartão e acesso a crédito, entre outros, cria-se progressivamente uma massa de informações sobre indivíduos cada vez mais dependentes (e em dívida) com o sistema financeiro. Mais adiante, refletiremos sobre a atual dominação financeira dos mercados e os discursos sobre o MEI, que incessantemente valorizam o acesso ao crédito como um dos grandes benefícios da categoria. Antes, porém, é preciso entender como foi possível que a ideia de cidadania tenha sido despedaçada e hoje se fale em uma "cidadania empresarial".

\section{Neoliberalismo e "cidadania empresarial"}

Assim como grande parte dos conceitos da Sociologia, cidadania não tem uma definição única e estanque, invariável ao longo do tempo. Certamente, não poderia ser diferente: como seria possível solidificar a noção de cidadania, se a própria sociedade sobre a qual ela se baseia mudou (e muda) com o passar dos anos? Aqui, apresentaremos as conceituações mais correntes a seu respeito, fornecendo o referencial básico que nos permita refletir sobre a atual proposição de uma "cidadania empresarial".

Segundo o sociólogo britânico TH Marshall (1967, p. 62), a cidadania seria um processo através do qual uma determinada sociedade atingiria uma igualdade qualitativa e substantiva entre seus indivíduos, que seriam "admitidos como membros completos da sociedade, isto é, como cidadãos". Progressivamente, a associação dos indivíduos na comunidade teria possibilitado formas de participação e conquistas de direitos que partiria das noções modernas de propriedade privada e liberdades individuais (cidadania civil), passando pelo avanço no exercício do poder através do voto (cidadania política) e chegando à aquisição coletiva de bem-estar e seguridade (cidadania social). Fazendo parte do projeto de sociedade moderna e industrial, a noção de cidadania como igualdade de direitos civis, políticos e sociais entre os cidadãos compensaria uma inevitável desigualdade econômica entre eles, algo entendido como inerente ao sistema capitalista. Assim, "a desigualdade do sistema de classes sociais pode ser aceitável desde que a 


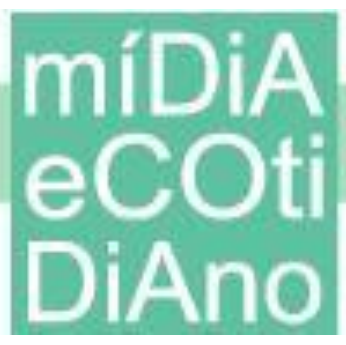

igualdade de cidadania seja reconhecida" (Ibid.). O reconhecimento de tal cidadania caberia ao Estado, de modo que, dentro do pensamento moderno (ou liberal) apresentado por Marshall, a cidadania lhe está intrinsecamente associada. Ou seja, o Estado seria a instância competente na comunhão dos indivíduos a partir de valores comuns e no reconhecimento de seu status de cidadãos, permitindo o acesso a determinados direitos concebidos a priori - direitos estes regulados e gerenciados pelo Estado.

Esse, claramente, é o caso do direito à Previdência Social acessível ao MEI. Trata-se de um direito social definido a priori, que busca proporcionar "um mínimo de bem-estar econômico e segurança" ao cidadão, possibilitando-o "participar, por completo, na herança social e levar a lida de um ser civilizado de acordo com os padrões que prevalecem na sociedade" (Ibid., p. 63-64). O direito a um CNPJ também pode ser pensado em termos de uma cidadania tradicional se o enquadrarmos como um direito civil, "necessário à liberdade individual" para, entre outras coisas, "concluir contratos válidos" e defender sua propriedade (Ibid., p. 63). Ambos os direitos são permitidos única e exclusivamente pelo Estado, instituição com poder de conferir benefícios aos indivíduos e criar um número (o CNPJ) que assume identidade e poderes mercadológicos.

Por outro lado, numa concepção mais contemporânea da cidadania (HOLSTON \& APPADURAI, 1996; CANCLINI, 2006; PORTILHO, 2010), a relação dual e hierárquica entre Estado e indivíduos seria questionada, dando margem para que outros atores (como segmentos da sociedade civil, empresas do $2^{\circ}$ setor, organizações do $3^{\circ}$ setor e grupos de mídia) façam parte do processo de constituição e reconhecimento de novos direitos, não mais determinados a priori pelo Estado, mas construídos cotidianamente em práticas e discursos que se referem às particularidades, crenças e necessidades de cada indivíduo. Para Canclini (2006), com a modernidade tardia e a globalização emergiria uma nova relação entre indivíduos, Estados e comunidades, mudando, portanto, a noção de cidadania, que deixa de estar restrita exclusivamente a um campo jurídico de direitos à igualdade civil e política, passando também a comportar aspectos culturais e sociais que clamam pelo direito à diferença e pela possibilidade de participação na construção daquilo que, para cada um, representa ser cidadão. Em resumo, seria a passagem de uma noção pré-estabelecida de cidadania, que tinha a pretensão de englobar a todos sob a grande crença de se construir uma sociedade igualitária e justa, para a possibilidade de se ter (e 


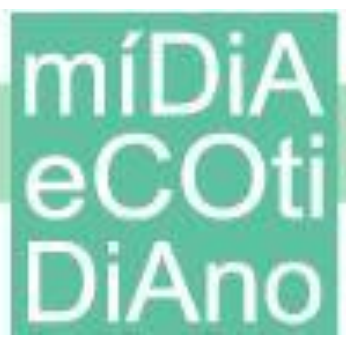

aceitar) múltiplas formas de exercício de cidadania, como "uma cidadania cultural, e também uma cidadania racial, outra de gênero, outra ecológica, e assim podemos continuar despedaçando a cidadania em uma multiplicidade infinita de reivindicações" (Ibid., p. 37). Nessa passagem, o valor referencial antes exercido pelo Estado migraria para o mercado, atual instituição modelar de regulação das condutas individuais.

É possível perceber um claro deslocamento entre os projetos tradicional e contemporâneo de cidadania. Dentro da concepção moderna, a cidadania foi idealizada como devendo ser homogênea entre os sujeitos, já que baseada nos princípios morais da igualdade. Seu propósito era produzir cidadãos dóceis, produtivos e incluídos no sistema capitalista através da noção de participação. No atual contexto neoliberal é possível pensar que a racionalidade imperativa é aquela mercadológica, a partir da qual a participação cidadã passa a ser segmentada em diversos nichos de consumo e quando o que vale é o mérito individual e não mais a igualdade social. O bom cidadão é aquele capaz de consumir e ser reconhecido pelas suas conquistas. Isso permite que alguns dos atuais "direitos de cidadania" sejam seletivamente distribuídos, não estando ao alcance de todos. Refiro-me, particularmente, ao acesso ao crédito e aos novos mercados, recorrentemente mencionado nos discursos sobre o MEI como vantagem de uma “cidadania empresarial” conquistada por essa nova figura jurídica.

Mas, afinal, o que seria uma "cidadania empresarial"? No círculo administrativo (seja acadêmico ou corporativo) a ideia de uma "cidadania empresarial" vem sendo pensada como "um conjunto de princípios e sistemas de gestão [na empresa] destinados à criação ou preservação de valor para a sociedade" (ALVES, 2001, p. 81). Trata-se da noção de que uma empresa, enquanto participante da sociedade, deve ter seus direitos reconhecidos (como liberdade de expressão ou reconhecimento social) e tem deveres a cumprir, sendo estes últimos ligados à responsabilidade ética e socioambiental.

Esta, no entanto, está longe de ser a concepção de "cidadania empresarial" utilizada nas matérias da mídia e nos materiais oficiais que tratam do MEI. O recorrente uso desta expressão a relaciona ao processo através do qual o trabalhador autônomo, antes irregular, formaliza-se e entra no mercado, podendo "usufruir de todas as vantagens do mundo formal", entre as quais estão "a possibilidade de participar das compras governamentais" e "a possibilidade de obter linhas de crédito em instituições financeiras 


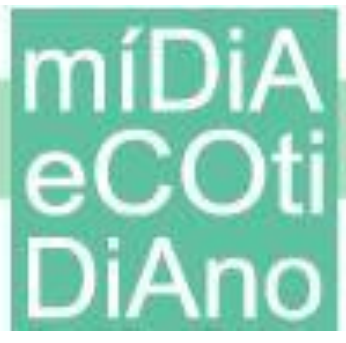

privadas e públicas de forma mais facilitada" (SEBRAE, 2009). Trata-se, como se percebe, de possibilidades que se abrem a partir do momento em que o individuo pessoa física é transformado em empresa, e não exatamente de direitos garantidos, uma vez que tal "cidadania empresarial" se inscreve nas lógicas concorrenciais do mercado, e não numa lógica de igualdade de direitos em processo de extinção. Se, como vimos, os benefícios da Previdência Social e do registro empresarial (CNPJ) são assegurados pelo Estado através da adesão ao programa; os benefícios do crédito e de entrada nos mercados não são colocados em termos de direitos garantidos, mas sim de possibilidade de acesso. O MEI, devidamente regularizado, seria o sujeito autorizado a participar de um mercado que se baseia na "justa competição" (EHRENBERG, 2010), o que não pressupõe a conquista obrigatória de determinados benefícios como crédito ou novos clientes, mas apenas sua colocação como postulante, como concorrente. A captação de mercados dependeria do aval de empresas e governos, potenciais fregueses de um MEI, enquanto a decisão sobre a cessão ou não do crédito cabe a uma das mais poderosas instituições hodiernas, a bancária. Dessa forma, o sucesso em transformar um potencial benefício em direito efetivo dependeria do próprio indivíduo, da sua eficiência em modos de agir tipicamente empresariais.

Este parece ser o pressuposto da já mencionada matéria "Primeiras receitas", que relata histórias de sucesso dos primeiros MEIs inscritos no programa. Dentre os que prosperaram, destaca-se a história do vendedor de bijuterias Adalberto Oliveira dos Santos, uma espécie de celebridade do universo MEI por ter sido o primeiro inscrito na categoria. Descrevendo-se dentro daquilo que Ehrenberg (2010) chama de "aventura empreendedora" do "indivíduo-trajetória", o acreano de origem simples que realizou a "façanha de tornar-se alguém" (Ibid., p. 172) afirma que "Ser desbravador tem vantagens (...) Dei mais de 500 entrevistas" (GUTIERREZ, 2012, p. EM 21). Sua "receita de sucesso" seria um misto de trabalho duro e sorte, já que o acesso a empréstimos que lhe possibilitaram prosperar não é uma garantia para todos: "Santos afirma que aderir ao programa o ajudou a conseguir empréstimos. Depois de honrar os pagamentos como pessoa jurídica, conseguiu crédito para comprar um apartamento." (Ibid.). Dos mais de 15 amigos e colegas de Adalberto que se tornaram MEI, nenhum conseguiu acesso a crédito. 
A constante menção à sorte (ou falta dela) na obtenção de crédito atesta uma visão seletiva e excludente do acesso a esse benefício, tão propalado pelos diversos discursos sobre o MEI como uma de suas vantagens. Assim, o crédito, mais novo item de uma noção de cidadania mercantilizada, disponível em teoria a todos que pagarem em dia o "Carnê da Cidadania", é na prática acessível somente a uma pequena parcela de indivíduos com destreza empresarial e sorte.

A “cidadania empresarial" dos MEIs pode, nesse sentido, ser pensada seguindo o raciocínio visto em Canclini (2006): trata-se de um fragmento de cidadania que confere sentido de pertencimento àqueles que a conquistam, satisfazendo-lhes certas necessidades (mercadológicas). Longe de ser igualitária e acessível a todos, a "cidadania empresarial" seria excludente não apenas por existir para alguns como objeto de consumo e para muitos como espetáculo (conforme atestam os discursos sobre o MEI), mas principalmente por deixar os indivíduos fora do processo decisório sobre o que efetivamente deveria ser uma cidadania empresarial, seus termos, condições e alcances... Ou seja, ao contrário de sua versão moderna, quando a cidadania supostamente significava um caminho democrático de participar nas tomadas de decisão da comunidade em que se está inserido, a atual versão empresarial da cidadania é duplamente excludente: para aqueles que não são capazes de ter acesso a ela e também para os que têm acesso, mas não podem deliberar sobre seu conteúdo ou condições. Ou alguém acredita que um MEI que toma um empréstimo tem alguma voz para opinar sobre os juros ou tarifas bancárias cobrados? Não nos esqueçamos que, ao falar em acesso ao crédito, estamos nos referindo necessariamente ao complexo bancário-financeiro, um dos mais poderosos mecanismos do sistema capitalista e, de acordo com muitos economistas, o principal responsável pela crescente desigualdade social que o mundo enfrenta hoje (DOWBOR, 2017; PIKETTY, 2014).

O capitalismo, porém, é engenhoso em seus argumentos de justificação e legitimação de valores. $\mathrm{O}$ alarmante abismo entre os mais ricos e os mais pobres, fato que hoje se manifesta em praticamente todos os países capitalistas do mundo, atualmente se reveste sob os discursos (midiáticos, institucionais, sociais) da "meritocracia". No atual contexto neoliberal, em que estruturas de protecção social criadas a partir do século XIX e legitimadas no século XX desmoronam, vemos prevalecer uma mentalidade que 


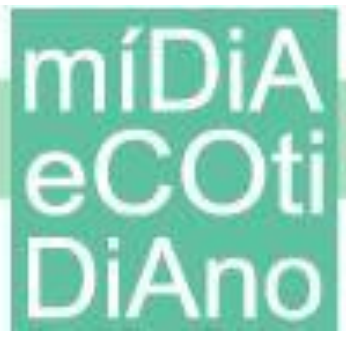

privilegia a performance individual e a concorrência interpessoal. Tal perspectiva endossa a meritocracia como um conjunto de valores que refuta privilégios hereditários ou corporativos e que avalia os indivíduos "independentemente de suas trajetórias e biografias sociais" (BARBOSA, 2003, p. 22). Para a antropóloga brasileira Lívia Barbosa, tal modo de pensar vem servindo de base à democracia desde a Revolução Francesa. No entanto, há nesse conceito um aspecto perverso, muitas vezes invisível nas análises mais superficiais: desconsidera-se as condições sociais objetivas enfrentadas pelos sujeitos em prol da apreciação da capacidade subjetiva de se destacar dos demais. Dessa forma, segundo Barbosa, o problema não é a avaliação de desempenho por si própria, mas sim a discordância sobre os critérios que mensuram os atributos individuais. Com isso, a meritocracia perde a sua eficiência enquanto mecanismo de combate à discriminação social inquestionável, passando a ser um critério de diferenciação, classificação e exclusão.

Diversos estudos atuais (FREIRE FILHO, 2010, 2011; CASTELLANO, 2018; JORGE, 2020) demonstram como os imaginários contemporâneos de sucesso e de alta performance estão profundamente associados à lógica meritocrática, ou seja, a um conjunto de valores segundo os quais as posições sociais e os ganhos dos mais variados sujeitos devem ser consequências de seus méritos e esforços individuais. Assim como outros objetos anteriormente analisados e que vêm progressivamente sucumbindo à lógica da performance e do mérito, sugiro estarmos diante de mais um caso: o MEI. Trata-se do indivíduo habilitado a performar como empreendedor e que, com mérito e resiliência, tem chances de prosperar, ainda que suas condições objetivas e subjetivas lhes sejam desfavoráveis ao combate mercadológico. Essa versão solitária e capilarizada do empreendedorismo contemporâneo reforça a construção de uma sociedade cada vez mais individualista, na qual até a noção de cidadania se "empresariza"...

\section{Conclusão}

O exame de alguns discursos institucionais e midiáticos permitiu perceber que a subjetividade do MEI ali construída está longe de ser específica. Ao contrário, engloba desde os mais excluídos dos brasileiros (como aqueles que dependem do auxílio do Bolsa Família), passando por "batalhadores" que garantem "sua sobrevivência por meio de 


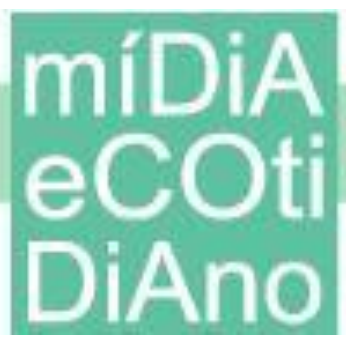

muito trabalho e de criatividade" e chegando até os integrantes de uma classe média instruída e com amplo potencial para decidir sobre seus destinos profissionais. Em comum, tais brasileiros teriam, segundo os discursos, o sonho de "tomar as rédeas da vida" e ter o próprio negócio, algo que se torna acessível à grande parte da população com uma nova legislação, através da qual o Estado brasileiro expurga parte de seus pecados e se redime aos olhos do mercado.

Há, no entanto, uma outra característica comum entre os MEIs que não é destacada pelos discursos midiáticos ou institucionais. Trata-se de uma nítida associação desta figura à racionalidade neoliberal, que prevê a privatização das relações e uma guinada individualista na sociedade, valorizando conquistas particulares através do discurso do mérito. Assim, para além de uma inédita faixa tributária e uma nova categoria de atuação mercadológica, o MEI promove e populariza uma renovada acepção de cidadania, a "cidadania empresarial". Lastreada no fundamento da livre concorrência, a cidadania empresarial - entendida no caso do MEI não como direitos, mas como possibilidade de acesso - se torna efetiva apenas para aqueles indivíduos adequados à lógica empresarial, ou seja, para os sujeitos ajustados, corpórea e mentalmente, à racionalidade empreendedora.

Debruçar-nos, ainda que brevemente, sobre algumas diferentes conceituações é um exercício fértil para refletir sobre as moralidades e normatividades que nos regem em cada momento histórico. A versão hodierna da cidadania, ajustada à lógica empresarial, nos indica com bastante clareza a primazia da racionalidade neoliberal e individualista sobre nossos modos de pensar e conceber a nós mesmos enquanto sujeitos. Não se trata de determinar qual "versão da cidadania" é melhor ou pior, nem mesmo de entrar num discurso saudosista, visto que mesmo em sua versão tradicional a cidadania guardava seus problemas. Trata-se de refletir sobre as atuais condições para poder, como afirma Portilho, "participar efetivamente da própria definição desse sistema e [realizar nosso] direito de definir aquilo no qual queremos ser incluídos" (PORTILHO, 2010, 192).

\section{Referências}

ALVES, Lauro Eduardo. Governança e cidadania empresarial. RAE, 41(4), 78-86, 2001.

BARBOSA, Lívia. Igualdade e meritocracia. Rio de Janeiro: FGV, 2003. 
CANCLINI, Nestor Garcia. Consumidores e cidadãos: Conflitos multiculturais da globalização. Rio de Janeiro: Editora UFRJ, 2006.

CASAQUI, Vander. Questões metodológicas para o estudo das vidas narrativizadas: aplicação às narrativas de empreendedores sociais. Famecos, Porto Alegre, v. 20, n. 3, p. 866-883, 2013 a.

Incorporações e sentidos do consumo em projetos de empreendimentos sociais portugueses: construção de marcas e publicização do espírito do tempo. Livro Café Intercom. UFPE, 2013b.

CASTELLANO, Mayka. Vencedores e Fracassados: O imperativo do sucesso na cultura da autoajuda. Curitiba: Editora Appris, 2018.

DOMINGOS, Guilherme Afif. Batalhadores do Brasil. Folha de S. Paulo, p. A3. Recuperado em https://acervo.folha.com.br/. Publicado em 17 de junho de 2015.

DOWBOR, Landislau. A era do capital improdutivo: Por que oito famílias têm mais riqueza do que metade da população do mundo?. São Paulo: Autonomia Literária, 2017.

EHRENBERG, Alain. O culto da performance: Da aventura empreendedora à depressão nervosa. São Paulo: Ideias \& Letras, 2010.

FOUCAULT, Michel. O nascimento da biopolítica. São Paulo, SP: Martins Fontes, 2008a.

Microfísica do poder. Rio de Janeiro: Edições Graal, 2008b.

A arqueologia do saber. Rio de Janeiro: Forense Universitária, 2019.

FREIRE FILHO, João, COELHO, Maria das Graças. (Orgs). A promoção do capital humano: Mídia, subjetividade e o novo espírito do capitalismo. Porto Alegre: Sulina, 2011.

FREIRE FILHO, João. (Org.). Ser feliz hoje: Reflexões sobre o imperativo da felicidade. Rio de Janeiro: FGV, 2010.

GAUTIÉ, Jérome. Da invenção do desemprego à sua desconstrução. Revista MANA: Estudos de Antropologia Social. 4 (2), 67-83, 1998.

GOMES, Helton Simões. Empreendedor individual supera micro e pequenas em dois anos. Folha de S. Paulo, p. B6. Recuperado em https://acervo.folha.com.br/. Publicado em 03 de agosto de 2012.

GUTIERREZ, Felipe. Primeiras receitas. Folha de S. Paulo, p. EM18 - EM22. Recuperado em https://acervo.folha.com.br/. Publicado em 19 de agosto de 2012.

HACKING, Ian. Making Up People. In: T.L. Heller et al. (Org). Reconstructing Individualism. Stanford: Stanford University Press, 1985.

HOLSTON, James, APPADURAI, Arjun. Cities and Citizenship. Public Culture, 8, p. 187204, 1996.

JORGE, Marianna Ferreira. Desempenho tarja preta: Medicalização da vida e espírito empresarial na sociedade contemporânea. Niterói, RJ: Eduff, 2020. 
MARSHALL, T. H. Cidadania, classe social e status. Rio de Janeiro: Zahar Editores, 1967.

MATOS, Patrícia. Férias sem fim ou o fim das férias?: capitalismo flexível, empreendedorismo e o estilo de vida nômade digital. In: CONGRESSO INTERNACIONAL COMUNICAÇÃO E CONSUMO, 2016, São Paulo. Anais [...]. São Paulo: ESPM, 2016.

PERRIN, Fernanda. Carreira solo. Folha de S. Paulo, p. F54-F55. Recuperado em https://acervo.folha.com.br/. Publicado em 13 de dezembro de 2015.

PIKETTY, Thomas. O capital no século XXI. Rio de Janeiro: Intrínseca, 2014.

PIMENTEL, José. Novo tempo com o Empreendedor Individual. Folha de S. Paulo, p. A3. Recuperado em https://acervo.folha.com.br/. Publicado em 08 de setembro de 2009.

PORTILHO, Fátima. Sustentabilidade ambiental, consumo e cidadania. São Paulo: Cortez, 2010.

ROXO, Marco; GROHMANN, Rafael. O jornalista empreendedor: uma reflexão inicial sobre jornalismo, flexibilização do trabalho e os sentidos do empreendedorismo no campo profissional. Líbero (FACASPER), v. 18, p. 123-131, 2015.

SALGADO, Julia. Entre solitários e solidários: o empreendedor como trabalhador ideal. Curitiba: Appris, 2020.

SALGADO, Julia; JORGE, Marianna Ferreira. "Mãe empreendedora": entre a promessa de uma subjetividade emergente e a frustração performática. E-COMPÓS, Brasília, v. 22, p. 1-19, 2019.

SENNETT, Richard. A corrosão do caráter: consequências pessoais do trabalho no novo capitalismo. Rio de Janeiro: Record, 2010.

SEBRAE. 5 anos: Microempreendedor Individual - MEI: um fenômeno de inclusão produtiva. Brasília, DF: Sebrae, 2015.

SEBRAE. Caderno do Empreendedor - Informe publicitário. Folha de S. Paulo, pp. 1-6. Recuperado em https://acervo.folha.com.br/. Publicado em 23 de dezembro de 2009.

SOUZA, Jessé. Ralé brasileira: Quem é e como vive. Belo Horizonte: Editora UFMG, 2009.

Os batalhadores brasileiros: Nova classe média ou nova classe trabalhadora? Belo Horizonte: Editora UFMG, 2012. 